\title{
Data-driven Age | Educating the Architects of Tomorrow
}

\author{
Nathan Howe \\ Kansas State University, USA \\ nhowe@ksu.edu \\ Ryan Gedney \\ HOK, USA \\ ryan.gedney@hok.com
}

\begin{abstract}
This paper delves into the paradigm shift of architecture practice and teaching in a data-driven age. What tools are needed within the architectural environment? What type of expertise must professionals be exposed to? What type of research and analysis is necessary to provide conviction for a design? These are just a few questions introduced in this paper to create a methodology for discovering alternate ways of teaching and practicing architecture. In this exploration, an architectural firm and a graduate studio's expertise were combined to create a framework for educating the architect of tomorrow in a data-driven age.
\end{abstract}

Keywords: data-drive; parameters; technology; architecture; urban; academy; profession

\section{Introduction}

Due to the rate of technological change continuing its parabolic acceleration, it is increasingly challenging to develop consistent habits in every aspect of our lives as individuals and as organizations. At this point most industries have accepted the idea that technology's effect on the way we develop and deliver products and services continues to change in bigger and more frequent ways. It's tough to keep up. As individual technology consumers, it is relatively easy to adapt to this change but as a large organization it is challenging. This frequent change in process is often fundamentally against the needs of a large university or firm to develop stable means and methods for teaching and executing what they do. Therefore, the near-constant topic of conversation is not only "how do we steer a large ship like a sports car" but also "how do we steer a sports car effectively when the steering wheel can also be a series of levers, buttons, or brain receptors"? The market of digital tools is vast. The options near limitless. By the time you intimately understand these options they will have changed dramatically.

In architecture, technology's effect on the design process is, for better or worse, mostly centered on increasing speed and precision of a design process which has existed since before the personal computer and internet (Terzidis 2006). A faster and more accurate pen and model making method has essentially been most of the advancement. However, what we analyze to determine solutions has grown massively in type and scale.

When consumed, organized, and visualized properly, massive data sets at the global and civic scale centered around human behavior, climate, building systems, physics simulation, etc. have given designers an unparalleled level of clarity in how everything behaves. It's not to say architects haven't thought to some degree about these new data frontiers before. They have. We're simply now quantifying more accurately the data and subsequently elevating a design response from intuitive to proven. This quality of proof has been the biggest leap (van Berkel \& Bos 2016). VR, AR, light simulation, climate data, behavioral data, are just a few highlighted leaps forward in design tools available now.

The basic process is simple. The logistics are not. The inherent challenge is to foster the practice and the university into fully engaging in this data-driven age and the technologies of tomorrow. Architects have been taught to integrate vast amounts of observational, environmental, behavioral, structural and poetic information, as a personified Howard Roark visionary; but this is no longer enough (Ratti \& Claudel, 2015). The architect needs to not only define the right questions to be asked, but also establish a series of evaluative goals which can be analyzed to achieve the best city, neighborhood, street, and building. Thus, increasing the potential intelligence and accuracy of the product and service they provide. The architect of tomorrow must also be prepared to work within this paradigm shift (Specher 2013). Within architecture there is so much information to consider that architecture firms must have generalists and specialists working together. The specializations range from experts in urban planning, data specialist, façade, parametric, and digital fabrication, to name a few. This new design team must formulate new ways of communicating and disseminating large amounts of data without losing sight of architectural aesthetic goals.

This type of shifting paradigm is difficult to navigate within the practice and the university. It is also challenging in both to evolve a teaching philosophy to bring everyone up to speed and be ready to engage in this ever-expanding data-driven age. This paper investigates this development and how an architectural firm and a graduate studio combined expertise to lay the groundwork for investigating how the university can best serve the profession and vice versa. 


\section{Methodology}

HOK a global firm generously sponsored the studio, lending their vast amount of project knowledge and financial support. The studio was designed to be an urban renewal data-driven think tank. The timeline for the project spanned over the course of the students' final two semesters of a graduate degree at Kansas State University. The city chosen for the studio was Atlanta. HOK had been working on large sports projects in the Atlanta downtown area for years and saw it is as ripe for a deep dive on urban research and renewal. After extensive greaterAtlanta research by the studio, it was determined that Atlanta's "gulch" area would be the site for planning rethink. This deserted wasteland, which had literally been used for zombie apocalyptic films, was in dire need of connecting it back to the city. Given its desolate environment and its demarcation of extreme socioeconomic and racial divide it had become an unofficial boundary between the have and have nots. The fall semester consisted of the studio performing extensive research and in the end creating a master plan for the "gulch" area for a projected Atlanta in the year 2040. In the latter part of the semester the students individually chose appropriate additional building types needed within the master planning research to be designed in the spring semester.

While that provided a framework for the content of the student work, the methodology of the firm-studio pairing was to create an environment of inquiry. The students were asked to use the graduate studio as a laboratory. They would be constantly questioning what were the best tools for architectural design. Were they thinking about the process of iteration correctly? What is the information they needed to make design decisions? What design reaction was correct given the harvested data? Was there even more data out there for harvesting if we had the technology or knew the correct door for entry? When designing a building how do you leverage data to help confirm design choices?

In this year of study not all questions were answered but in the asking, the studio could formulate a methodology that became

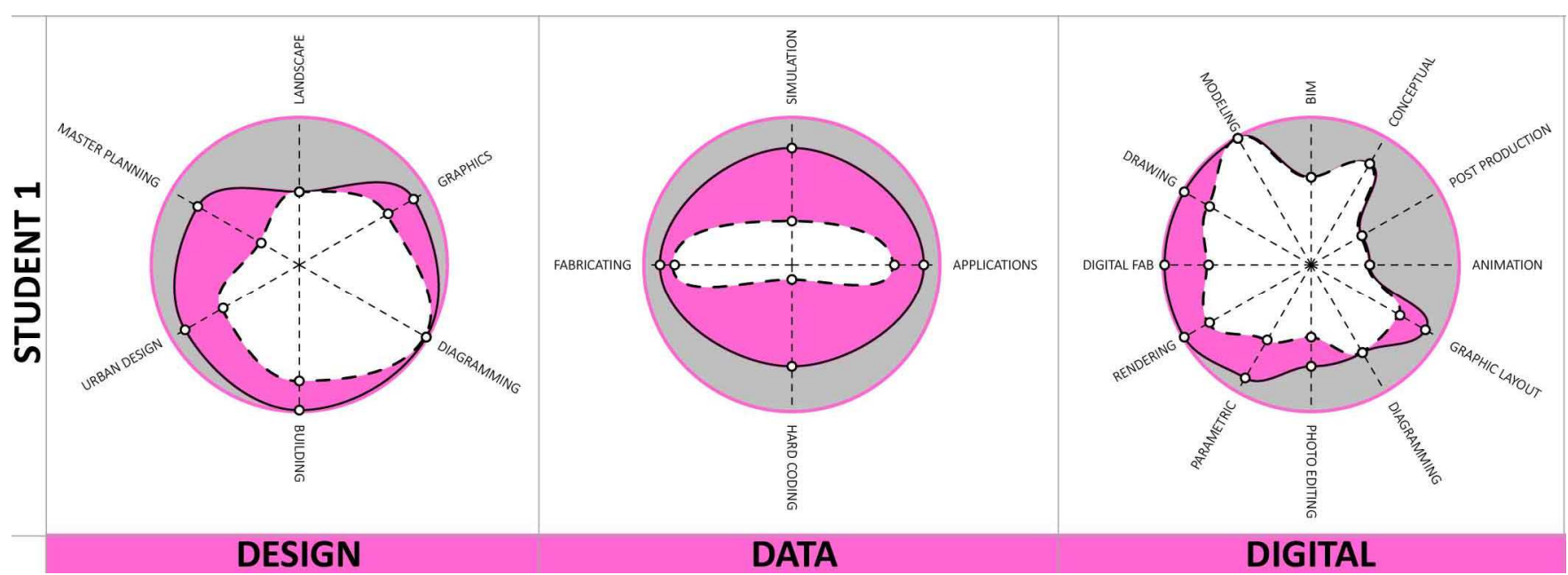

Figura 1: These radial data maps of the student's skills show a dash outlined white form in the center representing the student's skill at the beginning of their final graduate year. The second solid lined form represents the students increased strengths over the course of their final graduate year. a mantra "never go into default mode and always be seeking for the best tools for the job". Nothing was taken for granted. The ordinary ways of thinking would not do. The students would need to take a different approach in their design process which is normally rooted in working as an individual in the scale of building design's exterior to interior. What we would need to prepare them for is to work as a team and to consider the larger issues of socio-economics, demographics, historical tradition, and public transportation systems in its larger context of the city. These factors would end up playing a major part in their design.

\section{Learning Tools}

To help augment the studio, funding from the firm formed a base foundation for the studio to be able to research and eventually purchase various pieces of equipment that helped leverage the inquiry. If the tools were not on hand or could not be purchased, the studio took on the making of the tool. The origin of this method of making can be found in the first day of class when the instructor developed a tool to evaluate the student's mastery of design skills. This was a self-evaluation so it was far from a scientific investigation. The students filled out a spreadsheet of design skills from 1 to 10 (1, being a novice, to 10 representing mad skills and not afraid to use them) broken down into the following categories: hands-on, design, data, digital and leadership. These categories were then further divided into subcategories of more specific techniques. This tool was created to gauge the student's skill set to help the instructor and HOK tailor tasks to perceived strengths but then to also consider how to foster professed weaknesses. The spreadsheet was then automated in Grasshopper into radial data maps giving a visual snapshot of 

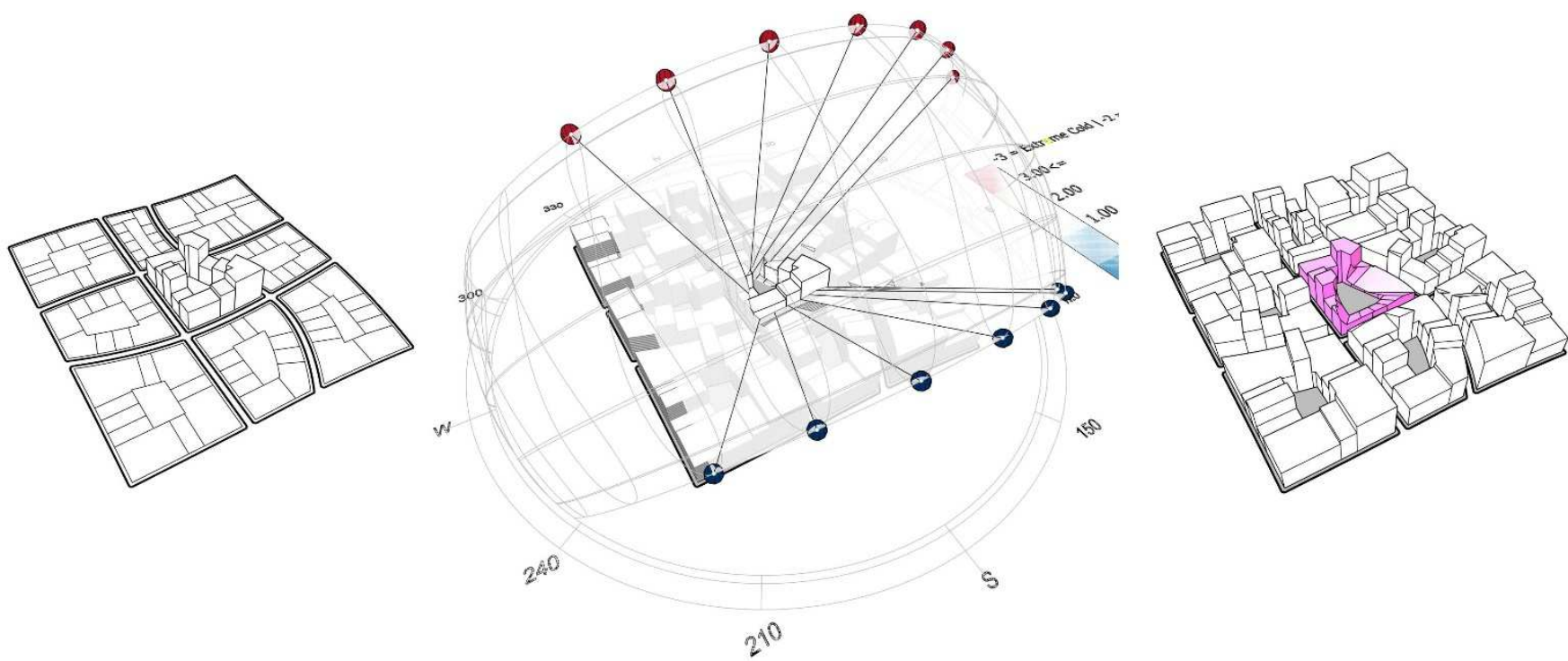

Figura 2: This example of the tutorials describes the potential massing variation given a mandatory 6 hour day of solar penetration into urban block interiors (DeKay \& Brown, 2014).

each student's skills. Figure 1 shows a small sample set of the results from two students in three of the categories.

Also, directing the teaching methodology was showing the students working methods of data-driven design. Our school is mostly steeped in a traditional architectural education with students being well grounded in balancing practice and theory of architectural design. Besides some supportive environmental courses which introduce environmental simulation, this studio formed the students first foray into using a more analytical performative measured approach to design. This gap in knowledge is not unlike what the profession deals with every day with updating new and old hires on new technologies as they come online.

To get the students oriented with data-driven processes, we organized a series of tool tutorials. These tutorials walked the students through techniques within the software and also the logic behind how to create sophisticated riggings using data logic. The tutorials were geared toward a "just in time" method of delivery. Each tutorial was delivered systematically through the two semesters with master planning issues in the first semester and building design information in the second. Some of the tutorials were as follows: urban creation (this developed basic street typology and building density rule sets), urban

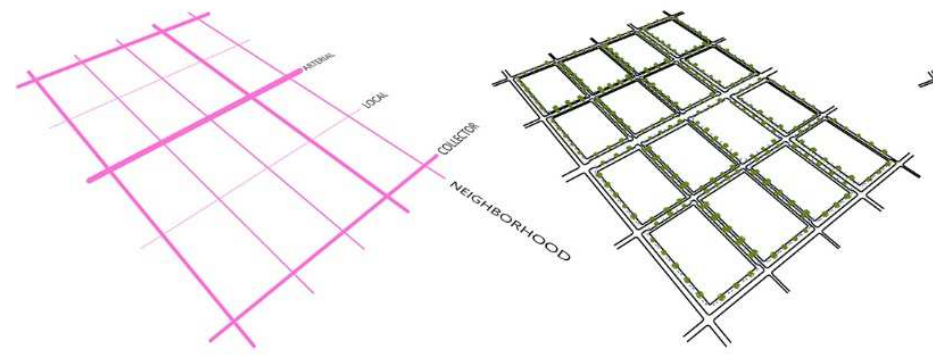

planning (this tutorial used a spreadsheet to simulate various zoning distribution alternatives) and urban solar analysis (this studied solar penetration to the streets and public spaces seen in Figure 2). As we moved from urban design to building design the tutorials also transformed in scale: building mass (conceptual tool to simulate a variety of massing alternatives given floor area ratio), program packing (using a spreadsheet of program spaces and sizes of a project, this tool conceptually packs the program into a building mass) and façade studies (this tutorial delved into tectonics of façade and solar analysis).

\section{Results}

Through "just in time" information delivery and analysis of student skill set, the students were organized in teams to achieve the master planning phase of the project. These teams evolved over time to not only fine tune strengths but to also help students weak in one area learn by example from someone strong in that area. While there are always growing pains in asking students to work in a coordinated effort, when most of their educational experience up to this point has been rather individually focused, this is an ever more important part of their education given that architectural practice is an everexpanding team effort. This need for collaboration is strengthened by organized meetings but also by tapping into each software's inherent tools for coordination. By setting
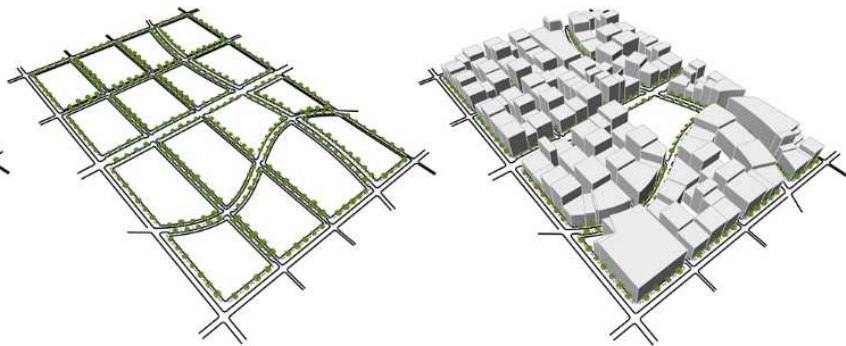

Figure 3: A series of screenshots of video showing how Chicken works. From a simple collection of street types, the component develops the 2D and 3D geometry for the city planning. One can see in the middle two images the street design can be as simple or as complex geometrically as needed. 
studio standards for layout, text styles, color palette, graphic styles, etc., the students discovered how to achieve a new level of quality in communicating their ideas to their critics and the leading experts in the field of design. By using work sessions in modeling software, the students could coordinate large amounts of information into a cohesive design. Keeping each other up to date on changes and corrections.

\section{Creating Tools}

They also learned to design tools to help in this coordination effort. The studio's predecessors, which went through a similar curriculum, had previously developed a tool for street design. They dubbed the Grasshopper (a visual scripting based plugin for Rhinoceros) component "Chicken" (given Grasshopper's penchant for naming apps after animals the "chicken cross the road" analogy was in play). This tool's function is to help design new street systems. Through the tool the designer could easily plug into each major street type, street aspects and parameters i.e. how many lanes, side street parking, bike lanes, tree lined, width for street furniture, etc. The students in charge of designing better streets for Atlanta 2040 included better mass transit stops and lanes for the autonomous car built into the system. Each street type could be customized and then populate the master plan. This allowed various alternatives to be evaluated by the team. Thus, accelerating the iterative process and a more educated decision-making process.
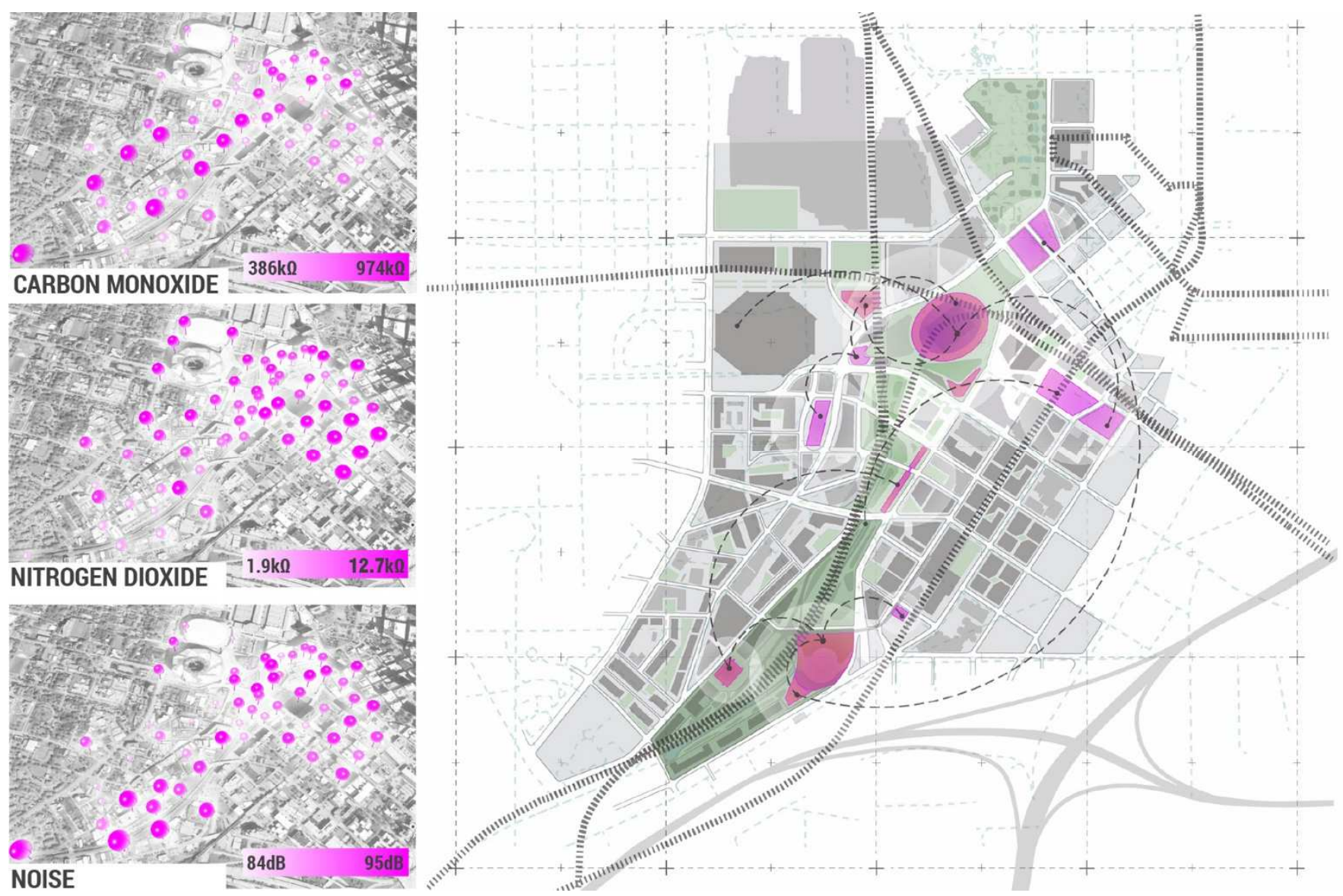

The studio also invested into smart city sensors which during our field work in Atlanta were distributed throughout the site to collect data for analysis. This was an extremely small sample size but this studio was designed to develop a culture for ways to think about information and implement the data into the design process. One will see a correlation to the green beltline the studio placed within the master plan (Figure 4) and the extreme carbon monoxide and nitrogen dioxide and noise spikes we recorded on site.

It is this type of deep dive into all aspects of Atlanta's history, zoning, social and economic strata, geopolitical makeup, transit system, etc. that made the university an essential part of the pairing between $\mathrm{HOK}$ and the studio. The end document collected all the research into one book to give a comprehensive window into a place and its potential of transforming a scar on the city into a vibrant new part of a growing metropolis (Howe et al. 2017).

As the students moved into their own building projects nestled anticipated needs of Atlanta. The projects explored were rather diverse from a Major League Soccer stadium, to a Brew Pub, a multi-use food and retail Bazaar, Performance Center, Boutique Hotel, etc. The connection with HOK once again was critical during the building project phase. Each student was paired with various professional experts in the student's within the master plan, the projects became quite varied given

Figure 4: On the left are data collected by the students using Smart City Sensors. The right image shows the eventual diagram of the master plan. The dash arcs show the connection student design projects would have with each other based on program and shared needs. 


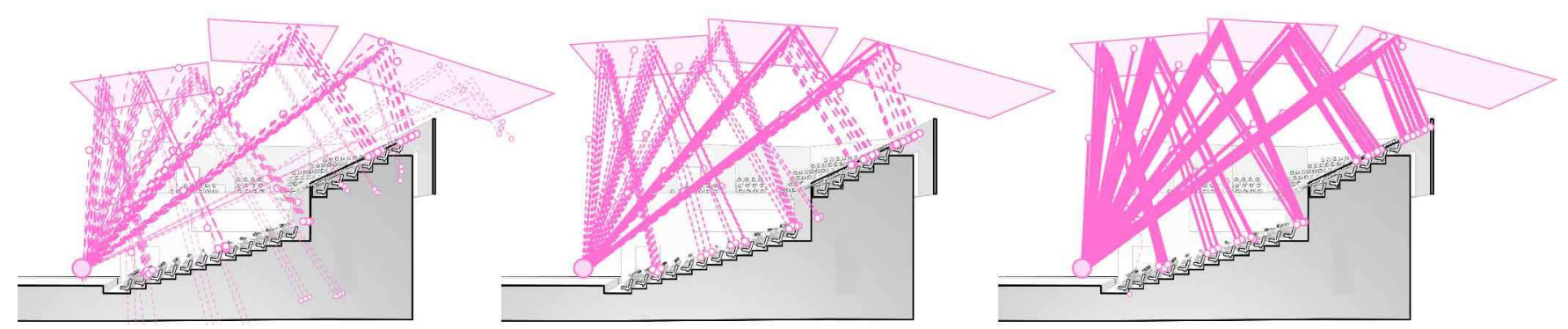

Figure 5: The images above show a series of screenshots of one of the student's studies to find the optimal angle and height for the ceiling planes to create the correct reverb times for the audience in a performance hall. The dashed lines represent various levels of acoustic problems. The final image on the right having the ideal positioning.

building type to have a one on one review of unique aspects of that building type.

\section{Parametric Study}

Each student also brought into their design a type of parametric research. Each experiment was customized to the building type. From acoustic analysis for performance halls, to shade studies for stadium design, to solar analysis for façade studies. The idea was not to have the parametric study design that aspect of the project but give conviction to the design objective.

The parametric analysis implements the potential power of computer-aided design. This aspect of the process has been the desired potential when the computer entered the architectural world in the 1980's but has only recently realized any critical result. Finally, software and computing power have reached a point where wading into the deep data is feasible. It is now on the profession and university to take advantage of these technological advancements. Thus, demanding a more potent formula for designing into the project objectives which can not only be reached but can be measured. This relationship of profession and university takes the next step in providing a baseline education to parametric and data-aided design.

Also, augmenting the exploration of design potentials is virtual reality and 3D printing. Thanks to HOK's funding we were able to engage in these technologies during the building design phase of the project. Whereas, currently, Virtual Reality (VR) is being mostly used as a tool to sell and communicate a project to clients in the practice. In a studio where the tool is readily accessible (this is the key) it became a way of verifying spatial, material and lighting decisions in a very precise way. Its potential as a design tool is extraordinary and in the few months that the studio used it, it became essential immediately. One cannot overstate the effect being able to

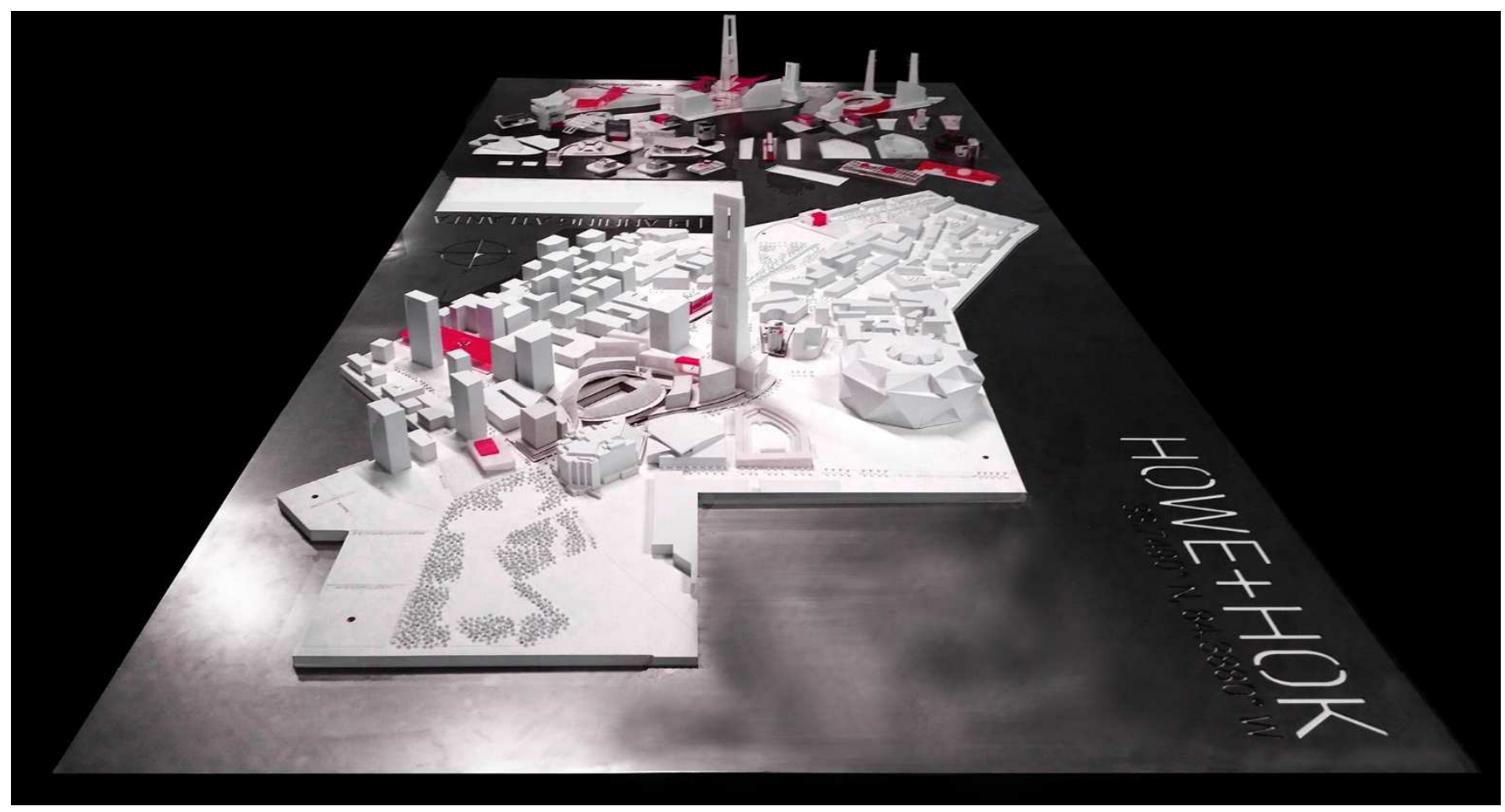

Figure 5: This studio model shows the extent of the master plan with the various projects planted throughout the city to provide stimulus for urban renewal. The model also housed in the background up to three of the many iterations of the students' projects built using the 3D print farm. 
walk through a space and validate decisions has for a designer.

Bringing four 3D printers into the iterative process also helped accelerate decisions at the macro scale. 3D printing is another technology which could have great benefits in revealing design characteristics to the naked eye just as with VR. However, the time delay between printing and actually holding the object in hand is rather steep. The studio found rather inexpensive 3D printers and with the funding were able to purchase four printers creating a printing farm for the studio.

\section{Discussion}

As we look ahead to the next major media wave which is arguably augmented reality and we combine it with artificial intelligence, we will likely see our steepest line on our human technological curve to date. Human decisions relying some or in part on artificial intelligence is a very real future we as designers must grapple. Real and artificial environments will blur together.

Today, in the world of architecture, "data-driven design" is a constant buzzword both in professional and academic circles. However, it is important to state that architects have always been data-driven. The difference now is that we can gather and analyze more data faster and more precisely through technology.

The other important acknowledgement is that the effect of speed and precision on design process does not allow for more design time due to automation of the tedious. Instead, at least in the professional world, timelines compress in the competitive market. Today tools allow us to execute faster than our minds can think. Prior to the personal computer, tools forced time for conviction. Competitive edge had little to do with tools and more to do with ideas. This is a major challenge in many industries. Artificial intelligence will fundamentally augment and embellish this challenge many fold in the next five years.

It should be a forgone conclusion that the architectural and urban design process and how we teach that process, is also continually changing. By partnering the university setting with the professional, universities better prepare students for the smart application of tools and techniques while the professional realm benefits from a deeper dive into areas of tech R\&D often challenging to attack in the competitive, profitdriven business world. Thus, it is hard not to take a negative view of what appears as quite the vicious cycle of technology. But, in the end, by embracing and understanding these methods, we can create the collective conviction and reserve to responsibly deploy them.

\section{References}

Dekay, M., \& Brown, G. Z. (2014). Sun, Wind and Light. (pp. e.41). Wiley.

Howe et al. (2017, July 15). https://rethinkatlanta.squarespace.com

Ratti, C., \& Claudel, M. (2015). Open-source architecture. (pp. 18-22). New York Thames \& Hudson.

Specher, A. (2013). "On the Affluence, Influence, and Confluence of Information." In Architecture In Formation. (pp. 23-26). Routledge

Terzidis, K. (2006). Algorithmic Architecture. Architectural Press. (pp. 37-60).

Van Berkel, B. \& Bos, C. (2016). Knowledge Matters. (pp. 37-52). FRAM $\exists$ 